\title{
Challenges associated with insulin therapy progression among patients with type 2 diabetes: Latin American MOSAlc study baseline data
}

\author{
Bruno Linetzky ${ }^{1 *}$, Brad Curtis ${ }^{2}$, Gustavo Frechtel ${ }^{3}$, Renan Montenegro Jr. $^{4}$, Miguel Escalante Pulido ${ }^{5}$
} Oded Stempa ${ }^{6}$, Janaina Martins de Lana ${ }^{7}$ and Juan José Gagliardino ${ }^{8}$

\begin{abstract}
Background: Poor glycemic control in patients with type 2 diabetes is commonly recorded worldwide; Latin America (LA) is not an exception. Barriers to intensifying insulin therapy and which barriers are most likely to negatively impact outcomes are not completely known. The objective was to identify barriers to insulin progression in individuals with type 2 diabetes mellitus (T2DM) in LA countries (Mexico, Brazil, and Argentina).

Methods: MOSAlc is a multinational, non-interventional, prospective, observational study aiming to identify the patient-, physician-, and healthcare-based factors affecting insulin intensification. Eligible patients were $\geq 18$ years, had T2DM, and were treated with insulin for $\geq 3$ months with/without oral antidiabetic drugs (OADs). Demographic, clinical, and psychosocial data were collected at baseline and regular intervals during the 24-month follow-up period. This paper however, focuses on baseline data analysis. The association between glycated hemoglobin (HbA1c) and selected covariates was assessed.

Results: A trend toward a higher level of $\mathrm{HbA1C}$ was observed in the LA versus non-LA population $(8.40 \pm 2.79$ versus $8.18 \pm 2.28 ; p \leq 0.069$ ). Significant differences were observed in clinical parameters, treatment patterns, and patient-reported outcomes in LA compared with the rest of the cohorts and between Mexico, Brazil, and Argentina. Higher number of insulin injections and lower number of OADs were used, whereas a lower level of knowledge and a higher level of diabetes-related distress were reported in LA. Covariates associated with HbA1c levels included age $(-0.0129 ; p<0.0001)$, number of OADs $(0.0835 ; p=0.0264)$, higher education level $(-0.2261 ; p=0.0101)$, healthy diet $(-0.0555 ; p=0.0083)$, self-monitoring blood glucose $(-0.0512 ; p=0.0033)$, hurried communication style in the process of care (0.1295; $p=0.0208)$, number of insulin injections $(0.1616 ; p=0.0088)$, adherence $(-0.1939$; $p \leq 0.0104)$, and not filling insulin prescription due to associated cost $(0.2651 ; p=0.0198)$.
\end{abstract}

Conclusion: MOSAlc baseline data showed that insulin intensification in LA is not optimal and identified several conditions that significantly affect attaining appropriate HbA1c values. Tailored public health strategies, including education, should be developed to overcome such barriers.

Trial Registration NCT01400971

Keywords: Type 2 diabetes, Latin America, Observational study, Quality of care, Psychological impact, Diabetes knowledge, Diabetes self-care management, Insulin treatment, Diabetes education

\footnotetext{
*Correspondence: linetzky_bruno@lilly.com

1 Eli Lilly and Company, Tronador 4890, Piso 12, CABA,

C1430DNN Buenos Aires, Argentina

Full list of author information is available at the end of the article
} 


\section{Background}

Although it is widely accepted that tight glycemic control is associated with a decreased risk of diabetes-related complications [1-5], poor control (herein defined as HbA1c $>7.0 \%)$ is commonly recorded worldwide and the available data show that Latin America (LA) is not an exception [6-11]. Despite clear treatment algorithms established within international guidelines, insulin therapy is frequently delayed even after long periods of poor metabolic control [12, 13]. Furthermore, observational data and evidence provided by multiple clinical trials implemented in different countries demonstrate a lack of treatment goal achievement among insulin-treated patients [14-18].

Although insulin therapy has been shown to significantly reduce glycated hemoglobin (HbA1c) levels, patients and physicians are often reluctant to initiate insulin therapy. Studies suggest that the reasons for this inertia on behalf of patients include a perceived lack of efficacy, negative impact on lifestyle, injection phobia, and fear of weight gain or hypoglycemic events [19]. Physician barriers include fears for their patients' safety (including weight gain and hypoglycemia), a perceived greater drain on physician's resources (time and cost), and concern that insulin regimens are too complex for patients to understand and will result in poor adherence [20]. Health care system factors, such as limited access to medication, care, and out of pocket expenditures, represent additional barriers to insulin therapy initiation [2123]. This multicomponent situation represents the major hurdles to overcome to achieve a successful initiation of, and persistence on, insulin therapy.

Despite these known barriers and their negative impact on the achievement of appropriate metabolic control, to the authors' knowledge no longitudinal study is currently available that attempts to address this important issue. Moreover, considering the scarce achievement of treatment goals in patients under insulin treatment, it is necessary to identify the barriers to intensifying insulin therapy and which of these barriers are most likely to impact outcomes.

The Multinational Observational Study Assessing Insulin use (MOSAIc) study is a multinational observational cohort study aiming at identifying the patient-, physician-, and health care environment-based factors associated with insulin initiation and progression in patients with type 2 diabetes mellitus (T2DM) in real-world practice. Data collected include demographic, clinical, and psychosocial indicators at the patient and physician level and practice site characteristics recorded at baseline and regular intervals during a 24-month follow-up period [24]. This analysis attempts to identify particular challenges faced by patients treated with insulin in LA. We have compared baseline demographic, clinical, and psychosocial characteristics of the overall MOSAIc cohort to that of three LA countries.

\section{Methods \\ Study design}

The rationale and design of the MOSAIc study have been reported elsewhere [24]. Briefly, MOSAIc is a multinational, non-interventional, prospective, observational cohort study due for completion in December 2015. Participants were recruited from July 2011 to July 2013 at 223 sites in 18 countries [United Arab Emirates (UAE), Argentina, Brazil, Canada, China, Germany, India, Israel, Italy, Japan, Mexico, Russia, Saudi Arabia, South Korea, Spain, Turkey, the UK, and the US (including Puerto Rico)].

Study sites represented a combination of specialist and general practice centers in urban and rural areas. Participants were followed for 2 years after study enrollment, with visit windows approximately $6,12,18$, and 24 months after the baseline visit, with such visits being part of their usual care.

The study was conducted following the ethical principles of the Helsinki Declaration, in accordance with good clinical practices and the applicable laws and regulations of the participant countries. The MOSAIc study was registered under ClinTrials.gov (NCT01400971). All patients completed informed consent forms approved by their country-specific institutional review boards (can be provided on request). The study's analytic plan has been approved by the Brigham and Women's Hospital Institutional Review Board.

\section{Study population}

Inclusion criteria for participation in MOSAIc were age $\geq 18$ years; diagnosis of T2DM; presentation to a study site as part of usual medical care; use of any commercially available initial insulin therapy for at least 3 months with or without any combination of approved non-insulin oral antidiabetic drugs (OADs) (e.g., metformin); and sufficient understanding of the primary language of the country to complete study surveys. Exclusion criteria were participation in another medical research study; use of intensive basal-bolus therapy (basal insulin in addition to three prandial doses); or initiation of insulin treatment with three daily injections of mixed insulin.

\section{Baseline data collection and patient-reported outcomes}

Patient data for demographic and clinical characteristics, comorbid conditions, and insulin regimen were retrospectively collected (limited to 6 months before the baseline visit) from medical records at the study site. 
Extensive information on patient-reported diabetesand insulin-related knowledge, attitudes, hypoglycemia, general health behaviors, patient-provider relationship, and perceived physical and psychological well-being were collected at baseline using self-report questionnaires.

The Brief Diabetes Knowledge Test was used to evaluate patients' understanding of their disease, such as how to manage insulin administration and how to treat hypoglycemia, with a summary score ranging from 0 (no questions correct) to 9 (all correct) [25].

The 17-item Diabetes Distress Scale was used to measure patients' degree of concern about different aspects of their type 2 diabetes care and treatment, using a six-point Likert scale ranging from "Not a problem" to "A very serious problem" [26]. Mean items score and standard deviation (SD) are reported.

The Insulin Specific Adherence Questionnaire was used to evaluate adherence to insulin therapy and included a question to assess patients' willingness to increase the frequency of injections. This question asked the participant to indicate to what extent he/she agreed with the statement: "I am willing to add additional injections to control my diabetes".

The 25-item Interpersonal Processes of Care (IPC) survey measured how patients' perceived the quality of their relationship with their providers over the past 12 months. Five alternative responses were provided for each question: 1 (never), 2 (rarely), 3 (sometimes), 4 (usually), and 5 (always). There are four positive IPC domains (elicited concerns, explained results, patient-centered decisions, and compassionate/respectful) in which higher scores correspond to better perceived interactions. Two IPC domains (hurried communication and discrimination) that were negatively framed in a way that better perceived interactions are represented by a lower score [27].

The Summary of Diabetes Self-Care Activities questionnaire was also administered in the study, analyzing three questions: "On how many of the last 7 days did you test your blood sugar the number of times recommended by your health-care provider?", "How many of the last 7 days have you followed a healthful eating plan?", and "On how many of the last 7 days did you participate in at least $30 \mathrm{~min}$ of physical activity?". Responses ranged from 0 to 7 [28].

\section{Statistical analysis}

Baseline participant characteristics were analyzed by region comparing LA participants with the rest of the cohort and by country comparing participants from Argentina, Brazil, and Mexico.

Categorical variables were described as the number and percentage of participants, and continuous variables were described using the mean and SD. Multiple imputation by Chained Equation was used to impute missing items [29]. Pooled analysis of variance (ANOVA) was used for continuous variables when comparing regional differences depending on whether the variables were imputed. Comparison of categorical variables was primarily undertaken using the Chi square test, except for insulin regimen where the Fisher's exact test was used. The Cochran-Mantel-Haenszel test was used when comparing the number of oral agents. Pooled multivariate linear regression models were used to assess the association between HbA1c and selected covariates. For all statistical analyses, the significance level was set at $\leq 0.05$. The imputation was done using Stata 13 (StataCorp LP; College Station, TX). All other analyses used SAS version 9.2 software (SAS Institute; Cary, NC).

\section{Results}

A total of 4341 patients met all MOSAIc eligibility criteria and comprised the analyzed population; 521 were from LA (Argentina $=160$; Brazil $=155$; Mexico $=206)$. Demographic, clinical, and metabolic characteristics are listed in Table 1. Data were grouped as LA and non-LA participants, as well as by the three different LA countries. Comparable age values were recorded in all groups. Patients from Argentina were significantly older than those from the other two LA countries $(\mathrm{p} \leq 0.0001)$.

The LA region had a higher percentage of female participants $(56.2 \%)$ compared to the global population, particularly in Brazil (64.5\%). Similarly, a significantly higher rate of participants with an education level of primary school or lower was also recorded in LA compared to non-LA countries (48.2 versus $27.2 \%$ ), particularly in Argentina (51.9\%) and Brazil (50.0\%). There was also a significant difference comparing the percentage of people with health insurance, with the lowest figures recorded in Mexico (25.2 \%). The LA population had a longer duration of diabetes than the overall MOSAIc cohort, with no significant difference among the three LA countries. Conversely, the rate of comorbidities (associated cardiovascular risk factors, microvascular complications, and macrovascular events) was lower in the LA population.

Baseline HbA1c levels were above the treatment targets recommended by international guidelines, with no significant differences among all the groups, although lower levels were recorded in the non-LA population $(8.40 \pm 2.79$ versus $8.18 \pm 2.28 ; \mathrm{p} \leq 0.069)$. Among LA countries, higher but not significantly different HbA1c values were recorded in Mexico (8.70 \pm 3.55$)$.

There were no significant differences between participants classified as overweight from LA or non-LA countries; conversely, there were significant differences among those classified as obese among countries, with 
Table 1 Demographic, clinical, and metabolic characteristics of the population by region and country

\begin{tabular}{|c|c|c|c|c|c|c|c|c|}
\hline & $\begin{array}{l}\text { All Mosaic } \\
\text { cohort }\end{array}$ & LA & $\begin{array}{l}\text { Non-LA } \\
\text { countries }\end{array}$ & $\mathrm{p}$ & Argentina & Brazil & México & $p$ \\
\hline Mean age, years (SD) & $61.77(11.02)$ & $61.99(11.21)$ & $61.74(10.99)$ & 0.6326 & $65.48(10.55)$ & $61.03(9.51)$ & $60.00(12.26)$ & $<0.0001$ \\
\hline Gender-females, n (\%) & $2176(50.1 \%)$ & $293(56.2 \%)$ & $1883(49.3 \%)$ & 0.0029 & $76(47.5 \%)$ & $100(64.5 \%)$ & $117(56.8 \%)$ & 0.0095 \\
\hline \multicolumn{9}{|l|}{ Education } \\
\hline Primary school, n (\%) & $1291(29.7 \%)$ & $251(48.2 \%)$ & 1040 (27.2\%) & $<0.0001$ & $83(51.9 \%)$ & 65 (41.9\%) & $103(50.0 \%)$ & 0.0474 \\
\hline $\begin{array}{l}\text { High school or more, } \\
\text { n (\%) }\end{array}$ & 2715 (62.5\%) & $235(45.1 \%)$ & 2480 (64.9\%) & & $69(43.1 \%)$ & $69(44.5 \%)$ & 97 (47.1\%) & \\
\hline \multicolumn{9}{|l|}{ Insurance } \\
\hline Private, $\mathrm{n}(\%)$ & $917(21.1 \%)$ & $134(25.7 \%)$ & $783(20.5 \%)$ & 0.0223 & $56(35.0 \%)$ & $48(31.0 \%)$ & $30(14.6 \%)$ & $<0.0001$ \\
\hline Public, n (\%) & $2229(51.3 \%)$ & $247(47.4 \%)$ & $1982(51.9 \%)$ & & $65(40.6 \%)$ & $76(49.0 \%)$ & $106(51.5 \%)$ & \\
\hline Uninsured, n (\%) & $848(19.5 \%)$ & $103(19.8 \%)$ & 745 (19.5 \%) & & $35(21.9 \%)$ & $16(10.3 \%)$ & $52(25.2 \%)$ & \\
\hline $\begin{array}{l}\text { Mean diabetes dura- } \\
\text { tion, years (SD) }\end{array}$ & $12.65(7.98)$ & $13.52(8.77)$ & $12.54(7.87)$ & 0.0083 & $13.71(9.77)$ & $13.46(7.78)$ & $13.42(8.69)$ & 0.9492 \\
\hline \multicolumn{9}{|l|}{ Comorbidities } \\
\hline $\mathrm{Ml}$ or $\mathrm{CAD}, \mathrm{n}(\%)$ & $824(19.0 \%)$ & $38(7.3 \%)$ & $786(20.6 \%)$ & $<0.0001$ & $16(10.0 \%)$ & $15(9.7 \%)$ & $7(3.4 \%)$ & 0.0217 \\
\hline Stroke, n (\%) & $151(3.5 \%)$ & $10(1.9 \%)$ & $141(3.7 \%)$ & 0.0384 & $4(2.5 \%)$ & $5(3.2 \%)$ & $1(0.5 \%)$ & 0.1393 \\
\hline $\begin{array}{l}\text { Congestive heart } \\
\text { failure, } \mathrm{n}(\%)\end{array}$ & $237(5.5 \%)$ & $6(1.2 \%)$ & $231(6.0 \%)$ & $<0.0001$ & $0(0.0 \%)$ & $3(1.9 \%)$ & $3(1.5 \%)$ & 0.2383 \\
\hline Nephropathy, n (\%) & $685(15.8 \%)$ & $48(9.2 \%)$ & $637(16.7 \%)$ & $<0.0001$ & $14(8.8 \%)$ & $17(11.0 \%)$ & $17(8.3 \%)$ & 0.6574 \\
\hline Neuropathy, n (\%) & 1194 (27.5 \%) & 85 (16.3\%) & 1109 (29.0\%) & $<0.0001$ & $14(8.8 \%)$ & $22(14.2 \%)$ & $49(23.8 \%)$ & 0.0004 \\
\hline Retinopathy, n (\%) & 954 (22.0 \%) & $78(15.0 \%)$ & $876(22.9 \%)$ & $<0.0001$ & $24(15.0 \%)$ & $24(15.5 \%)$ & $30(14.6 \%)$ & 0.9709 \\
\hline Depression, n (\%) & $370(8.5 \%)$ & $46(8.8 \%)$ & $324(8.5 \%)$ & 0.7899 & $4(2.5 \%)$ & $16(10.3 \%)$ & $26(12.6 \%)$ & 0.0024 \\
\hline Hypertension, n (\%) & 2994 (69.0 \%) & $335(64.3 \%)$ & 2659 (69.6\%) & 0.0140 & $112(70.0 \%)$ & $110(71.0 \%)$ & $113(54.9 \%)$ & 0.0013 \\
\hline Hyperlipidemia, n (\%) & 2484 (57.2\%) & $259(49.7 \%)$ & 2225 (58.2 \%) & 0.0002 & $81(50.6 \%)$ & $93(60.0 \%)$ & $85(41.3 \%)$ & 0.0019 \\
\hline HbA1c, mean (SD) & $8.20(2.47)$ & $8.40(2.79)$ & $8.18(2.28)$ & 0.0686 & $8.08(2.05)$ & $8.34(2.38)$ & $8.70(3.55)$ & 0.1108 \\
\hline $\begin{array}{l}\text { HbA1c physician } \\
\text { reported goal (SD) }\end{array}$ & $7.02(0.77)$ & $7.10(0.76)$ & $7.01(0.73)$ & 0.011 & $7.17(0.65)$ & $7.11(0.89)$ & $7.04(0.79)$ & 0.2917 \\
\hline BMI, mean (SD) & $29.58(6.39)$ & $29.78(5.64)$ & $29.55(6.49)$ & 0.4437 & $31.24(6.22)$ & $30.21(5.46)$ & $28.32(4.81)$ & $<0.0001$ \\
\hline $\begin{array}{l}\text { Systolic blood pressure, } \\
\text { mean (SD) }\end{array}$ & $132.42(16.83)$ & $132.94(17.24)$ & $132.34(16.72)$ & 0.4395 & 133.64 (13.69) & 135.49 (19.88) & $130.49(17.54)$ & 0.0214 \\
\hline
\end{tabular}

$B M I$ body mass index, $C A D$ coronary artery disease, $L A=$ Latin America, $M I$ myocardial infarction, $S D$ standard deviation

the highest and lowest rates recorded in Argentina and Mexico, respectively ( $\mathrm{p} \leq 0.0001)$.

Systolic blood pressure values were close to target values recommended by international guidelines, with Brazil and Mexico having the highest and lowest values, respectively $(\mathrm{p}=0.0214)$.

Treatment patterns varied across countries included in the study (Table 2). A higher number of daily insulin injections were reported in LA compared to non-LA countries, with Argentina having significantly more reported insulin injections compared to Brazil and Mexico ( $\mathrm{p} \leq 0.0001$ for both). Basal insulin alone was more frequently used in LA than in the rest of the MOSAIc cohort, with the highest rate recorded in Brazil among LA countries (74.8 \%; $\mathrm{p} \leq 0.0001)$. A higher percentage of LA participants also required basal insulin more than once per day. Important differences were also recorded in the use of concomitant OADs agents between the LA and non-LA population, as well as within LA countries ( $\mathrm{p} \leq 0.0001$ for both).
Metformin was the most commonly utilized therapy, with the highest and lowest figures recorded in Brazil and Mexico, respectively ( $\mathrm{p} \leq 0.0001)$.

Individual Diabetes Knowledge scores were low in the overall MOSAIc population, with lower figures in the LA versus non-LA countries $(4.16 \pm 2.23$ versus $4.89 \pm 2.19$; $\mathrm{p}<0.0001)$. The lowest figures were recorded in Mexico $(3.93 \pm 2.10)$ and Brazil $(3.88 \pm 1.91)(\mathrm{p}=0.0002)$ (Table 3).

A small but statistically significant difference was observed in the patients' Diabetes Distress Scale scores between LA and the rest of the study population ( $\mathrm{p} \leq 0.0001)$; an important and significant difference was also observed among LA countries, with highest level of distress recorded in Brazil (3.14 \pm 1.36$)$ and the lowest in Argentina $(2.17 \pm 1.19)(\mathrm{p} \leq 0.0001)$ (Table 3$)$.

The summary of self-care activities questionnaire showed a lower number of days with at least $30 \mathrm{~min}$ of physical activity reported among study participants 
Table 2 Treatment patterns by region and country

\begin{tabular}{|c|c|c|c|c|c|c|c|c|}
\hline & $\begin{array}{l}\text { All Mosaic } \\
\text { cohort }\end{array}$ & LA & $\begin{array}{l}\text { Non-LA } \\
\text { countries }\end{array}$ & $p$ & Argentina & Brazil & México & $\mathrm{p}$ \\
\hline $\begin{array}{l}\text { Freq of insulin injections/ } \\
\text { day mean }\end{array}$ & $1.63(0.68)$ & $1.80(0.68)$ & $1.60(0.67)$ & $<0.0001$ & $1.99(0.76)$ & $1.73(0.73)$ & $1.69(0.54)$ & $<0.0001$ \\
\hline \multicolumn{9}{|l|}{ Insulin regimen } \\
\hline \multicolumn{9}{|l|}{ Basal insulin only } \\
\hline Overall, n (\%) & 2168 (49.9\%) & $365(70.1 \%)$ & $1803(47.2 \%)$ & $<0.0001$ & $103(64.4 \%)$ & $116(74.8 \%)$ & $146(70.9 \%)$ & $<0.0001$ \\
\hline Once, n (\%) & 1656 (76.4 \%) & $152(41.6 \%)$ & 1504 (83.4 \%) & & $37(35.9 \%)$ & $52(44.8 \%)$ & $63(43.2 \%)$ & \\
\hline More than once, $\mathrm{n}(\%)$ & $512(23.6 \%)$ & $213(58.4 \%)$ & $299(16.6 \%)$ & & $66(64.1 \%)$ & 64 (55.2 \%) & $83(56.8 \%)$ & \\
\hline \multicolumn{9}{|l|}{ Mixed insulin only } \\
\hline Overall, n (\%) & 1284 (29.6\%) & $70(13.4 \%)$ & $1214(31.8 \%)$ & & $36(22.5 \%)$ & $0(0.0 \%)$ & $34(16.5 \%)$ & \\
\hline Once, n (\%) & $112(8.7 \%)$ & $4(5.7 \%)$ & $108(8.9 \%)$ & & $1(2.8 \%)$ & $0(0.0 \%)$ & $3(8.8 \%)$ & \\
\hline More than once, n (\%) & 1172 (91.3\%) & $66(94.3 \%)$ & 1106 (91.1\%) & & $35(97.2 \%)$ & $0(0.0 \%)$ & $31(91.2 \%)$ & \\
\hline \multicolumn{9}{|l|}{ Short acting only } \\
\hline Overall, n (\%) & 170 (3.9\%) & $11(2.1 \%)$ & $159(4.2 \%)$ & & $1(0.6 \%)$ & $1(0.6 \%)$ & $9(4.4 \%)$ & \\
\hline Once, n (\%) & 37 (21.8\%) & $2(18.2 \%)$ & 35 (22.0\%) & & $1(100.0 \%)$ & $0(0.0 \%)$ & $1(11.1 \%)$ & \\
\hline More than once, n (\%) & $133(78.2 \%)$ & $9(81.8 \%)$ & $124(78.0 \%)$ & & $0(0.0 \%)$ & $1(100.0 \%)$ & $8(88.9 \%)$ & \\
\hline \multicolumn{9}{|l|}{ Other insulin combinations } \\
\hline Overall, n (\%) & $597(13.8 \%)$ & $64(12.3 \%)$ & $533(14.0 \%)$ & & $20(12.5 \%)$ & $27(17.4 \%)$ & $17(8.3 \%)$ & \\
\hline Once, n (\%) & $172(28.8 \%)$ & $14(21.9 \%)$ & $158(29.6 \%)$ & & $2(10.0 \%)$ & $9(33.3 \%)$ & $3(17.6 \%)$ & \\
\hline More than once, n (\%) & $425(71.2 \%)$ & $50(78.1 \%)$ & $375(70.4)$ & & $18(90.0 \%)$ & $18(66.7 \%)$ & $14(82.4 \%)$ & \\
\hline \multicolumn{9}{|c|}{ Other antidiabetic medication } \\
\hline No. of OADs, mean (SD) & $1.22(1.09)$ & $0.84(0.88)$ & $1.27(1.10)$ & $<0.0001$ & $0.66(0.68)$ & $1.33(0.91)$ & $0.61(0.84)$ & $<0.0001$ \\
\hline Metformin, n (\%) & 2437 (56.1 \%) & $280(53.7 \%)$ & $2157(56.5 \%)$ & 0.2400 & $82(51.3 \%)$ & $122(78.7 \%)$ & $76(36.9 \%)$ & $<0.0001$ \\
\hline Sulfonylurea, n (\%) & $1389(32.0 \%)$ & $92(17.7 \%)$ & $1297(34.0 \%)$ & $<0.0001$ & $13(8.1 \%)$ & $55(35.5 \%)$ & $24(11.7 \%)$ & $<0.0001$ \\
\hline $\begin{array}{l}\text { Dipeptidyl peptidase-4 } \\
\text { inhibitor, } \mathrm{n}(\%)\end{array}$ & $538(12.4 \%)$ & $38(7.3 \%)$ & $500(13.1 \%)$ & 0.0002 & $2(1.3 \%)$ & $20(12.9 \%)$ & $16(7.8 \%)$ & 0.0003 \\
\hline $\begin{array}{l}\text { Alpha-glucosidase inhibi- } \\
\text { tor, } \mathrm{n}(\%)\end{array}$ & $321(7.4 \%)$ & $7(1.3 \%)$ & $314(8.2 \%)$ & $<0.0001$ & $1(0.6 \%)$ & $2(1.3 \%)$ & $4(1.9 \%)$ & 0.5536 \\
\hline GLP-1, n (\%) & $143(3.3 \%)$ & $5(1.0 \%)$ & $138(3.6 \%)$ & 0.0015 & $2(1.3 \%)$ & $2(1.3 \%)$ & $1(0.5 \%)$ & 0.6678 \\
\hline Other drug, n (\%) & $443(10.2 \%)$ & $14(2.7 \%)$ & $429(11.2 \%)$ & $<0.0001$ & $5(3.1 \%)$ & $5(3.2 \%)$ & 4 (1.9\%) & 0.6952 \\
\hline
\end{tabular}

GLP1 Glucagon-like peptide-1, LA Latin America, OADs oral antidiabetic drugs, SD standard deviation

in LA. Comparison of the number of days performing self-monitoring activities among the three LA countries showed higher values in Argentina, higher number of days following a healthy diet in Argentina and Brazil, and more days with physical activity practices in Mexico (Table 3).

A similar level of adherence was reported in LA compared to the rest of the MOSAIc participants, but a trend to a lower level of adherence was reported in Brazil (67.1\%). LA patients expressed more willingness to add additional injections to control their diabetes (67.4 versus $53.2 \% ; \mathrm{p}<0.0001$ ).

Although no significant difference in the rate of not filling the prescription due to cost was observed between LA and the rest of the MOSAIc cohort, important variations were observed at the country level, with the lowest and highest rates in Argentina and Mexico, respectively $(\mathrm{p}=0.0004)$.
Differences in the nature of the reported patienthealth care provider relationship are depicted in Table 3. Lower levels of "hurried communication" were reported in Argentina, as well as higher scores in the domains of "elicited concerns", "explained results", "compassionate and respectful style", and "patient centered decision making", compared to the other LA countries.

Table 4 shows the analysis of variables associated with HbA1c levels. After the adjustment for potential confounders, patients in LA countries had similar levels of HbA1c compared to the rest of the MOSAIc cohort. The variables significantly associated with $\mathrm{HbA1c}$ levels were age $(-0.0129 ; \mathrm{p}<0.0001)$, number of other OADs $(0.0835 ; \mathrm{p}=0.0264)$, having higher education level $(-0.2261 ; \mathrm{p}=0.0101)$, following a healthy diet $(-0.0555 ; \mathrm{p}=0.0083)$, self-monitoring blood glucose $(-0.0512 ; \mathrm{p}=0.0033)$, a hurried communication style in the interpersonal process of care questionnaire $(0.1295$; 
Table 3 Self-reported outcomes by region and country

\begin{tabular}{|c|c|c|c|c|c|c|c|c|}
\hline & $\begin{array}{l}\text { All Mosaic } \\
\text { cohort }\end{array}$ & LA & $\begin{array}{l}\text { Non-LA } \\
\text { countries }\end{array}$ & $\mathrm{p}$ & Argentina & Brazil & México & $\mathrm{p}$ \\
\hline Diabetes knowledge, mean (SD) & $4.80(2.26)$ & $4.16(2.23)$ & $4.89(2.19)$ & $<0.0001$ & $4.72(2.30)$ & $3.88(1.91)$ & $3.93(2.10)$ & 0.0002 \\
\hline DDS total, mean (SD) & $2.27(1.14)$ & $2.49(1.32)$ & $2.24(1.11)$ & $<0.0001$ & $2.17(1.19)$ & $3.14(1.36)$ & $2.26(1.21)$ & $<0.0001$ \\
\hline \multicolumn{9}{|l|}{ Self-care activities } \\
\hline Self-monitoring, mean (SD) & $3.60(2.62)$ & $3.70(2.68)$ & $3.58(2.64)$ & 0.3238 & $4.89(2.52)$ & $3.30(2.64)$ & $3.09(2.52)$ & $<0.0001$ \\
\hline General diet, mean (SD) & $4.44(2.24)$ & $4.57(2.21)$ & $4.42(2.24$ & 0.1576 & $4.86(2.02)$ & $3.89(2.49)$ & $4.85(2.11)$ & $<0.0001$ \\
\hline Exercise mean (SD) & $2.86(2.44)$ & $2.42(2.40)$ & $2.92(2.43)$ & $<0.0001$ & $2.14(2.32)$ & $1.93(2.35)$ & $3.01(2.37)$ & $<0.0001$ \\
\hline $\begin{array}{l}\text { Adherence (does not miss shots), } \\
\text { n (\%) }\end{array}$ & $3290(75.8 \%)$ & $398(76.4 \%)$ & $2892(75.7 \%)$ & 0.7793 & $134(83.8 \%)$ & $104(67.1 \%)$ & $160(77.7 \%)$ & 0.0622 \\
\hline $\begin{array}{l}\text { Willingness to add additional } \\
\text { injection, } \mathrm{n}(\%)\end{array}$ & $2383(54.9 \%)$ & $351(67.4 \%)$ & $2032(53.2 \%)$ & $<0.0001$ & $99(61.9 \%)$ & $107(69.0 \%)$ & $145(70.4 \%)$ & 0.1973 \\
\hline $\begin{array}{l}\text { Not fill in insulin prescription due } \\
\text { to cost, } \mathrm{n}(\%)\end{array}$ & $460(10.6 \%)$ & $53(10.2 \%)$ & $407(10.7 \%)$ & 0.5832 & $6(3.8 \%)$ & $14(9.0 \%)$ & $33(16.0 \%)$ & 0.0004 \\
\hline \multicolumn{9}{|l|}{ IPC } \\
\hline $\begin{array}{l}\text { Hurried communication, mean } \\
\text { (SD) }\end{array}$ & $1.57(0.70)$ & $1.53(0.77)$ & $1.58(0.69)$ & 0.1184 & $1.25(0.42)$ & $1.69(0.80)$ & $1.62(0.88)$ & $<0.0001$ \\
\hline Elicited concerns, mean (SD) & $3.92(1.05)$ & $3.73(1.18)$ & $3.95(1.03)$ & $<0.0001$ & $4.15(0.91)$ & $3.51(1.17)$ & $3.56(1.25)$ & $<0.0001$ \\
\hline $\begin{array}{l}\text { Explained results-medications, } \\
\text { mean (SD) }\end{array}$ & $3.92(1.02)$ & $4.03(1.04)$ & $3.91(1.01)$ & 0.0110 & $4.41(0.68)$ & $3.84(1.07)$ & $3.87(1.17)$ & $<0.0001$ \\
\hline $\begin{array}{l}\text { Patient-centered decision mak- } \\
\text { ing, mean (SD) }\end{array}$ & $3.37(1.22)$ & $3.30(1.35)$ & $3.37(1.20)$ & 0.2293 & $3.74(1.15)$ & $2.87(1.20)$ & $3.29(1.47)$ & $<0.0001$ \\
\hline $\begin{array}{l}\text { Compassionate, respectful, } \\
\text { mean (SD) }\end{array}$ & $4.10(0.89)$ & $4.16(0.97)$ & $4.10(0.87)$ & 0.1189 & $4.53(0.61)$ & $4.12(0.99)$ & $3.90(1.11)$ & $<0.0001$ \\
\hline Discriminated, mean (SD) & $1.50(0.73)$ & $1.43(0.67)$ & $1.51(0.73)$ & 0.0123 & $1.45(0.69)$ & $1.37(0.68)$ & $1.46(0.66)$ & 0.4117 \\
\hline
\end{tabular}

DDS Diabetes Distress Scale, IPC Interpersonal Processes of Care, LA Latin America

$\mathrm{p}=0.0208)$, the number of insulin injections $(0.1616$; $\mathrm{p}=0.0088)$, being adherent to the insulin treatment $(-0.1939 ; \mathrm{p}=0.0104)$, and no insulin prescription adherence due to associated cost $(0.2651 ; \mathrm{p}=0.0198)$.

\section{Discussion}

The current analysis of MOSAIc study baseline data provides relevant information regarding the potential challenges that individuals with T2DM face when using insulin in LA countries. Although people from the three LA countries included in the study share some of these challenges with the whole cohort, others appear to be more specific for the region. These findings highlight, from a public health perspective, the importance of implementing more locally tailored solutions to optimize blood glucose control in individuals with T2DM treated with insulin.

A common problem recorded was the poor degree of metabolic control (HbA1c $\approx 8 \%$ ), that coincides with data reported consistently in previous studies $[7,9,10$, 30].

This poor metabolic control was observed despite the wide variety of treatment patterns recorded in the studied population; in fact, patients in the three LA countries have a different treatment pattern compared to other regions, namely, a higher rate of basal insulin use and a lower rate of OADs agents used. Conversely, a comparable rate of metformin prescription was recorded in LA and non-LA countries. However, metformin was differently prescribed in LA countries, with a higher rate in Brazil (78.7 \%) and a lower rate in Mexico (37 \%). The recommendation of Asociación Latinoamericana de Diabetes (ALAD) guidelines regarding the use of metformin and precaution with the use of sulfonylureas may explain, at least partly, such a prescription pattern [31].

The low rate of incretin therapies use is also noteworthy, despite data showing that they are associated with a better HbA1c control and a lower risk of hypoglycemia and weight gain compared to insulin treated patients [32-34]. Clearly, none of the variety of treatment alternatives employed were effective in attaining the $\mathrm{HbA1c}$ target values recommended by international guidelines to prevent development and progression of chronic complications.

The linear regression analysis identified many variables associated with attainment of HbA1c treatment goals, with some of them unmodifiable (such as the age of the patients). Similar results have been reported in the ABCs of good management study in China [35, 36].

Other variables identified were the number of other associated OADs, the number of insulin injections, and adherence to insulin treatment, demonstrating once 
Table 4 Variables associated with HBA1c levels (univariate and multivariate analysis)

\begin{tabular}{|c|c|c|c|c|c|c|}
\hline & Unadjuste & ession & & Adjusted $\mathrm{r}$ & ion & \\
\hline & Estimate & $95 \% \mathrm{Cl}$ & $\mathrm{p}$ & Estimate & $95 \% \mathrm{Cl}$ & $p$ value \\
\hline Age & -0.0206 & $(-0.03,-0.02)$ & $<0.0001$ & -0.0129 & $(-0.02,-0.01)$ & 0.0001 \\
\hline Gender-female & 0.1085 & $(-0.01,0.23)$ & 0.0735 & 0.0589 & $(-0.07,0.19)$ & 0.3632 \\
\hline Diabetes duration & -0.0054 & $(-0.01,0.00)$ & 0.1866 & 0.0036 & $(-0.01,0.01)$ & 0.4219 \\
\hline BMI & 0.0114 & $(-0.00,0.02)$ & 0.0643 & 0.0075 & $(-0.00,0.02)$ & 0.2243 \\
\hline Number of OAD & 0.0631 & $(-0.00,0.13)$ & 0.0639 & 0.0835 & $(0.01,0.16)$ & 0.0264 \\
\hline Insulin-mixed only & 0.1715 & $(0.03,0.31)$ & 0.0143 & 0.0402 & $(-0.14,0.22)$ & 0.6625 \\
\hline Short acting only & 0.4457 & $(0.11,0.78)$ & 0.0098 & 0.3583 & $(-0.00,0.72)$ & 0.0506 \\
\hline Other & 0.2045 & $(0.02,0.39)$ & 0.0323 & 0.0892 & $(-0.11,0.29)$ & 0.3717 \\
\hline Country group $-\mathrm{LA}$ & 0.2248 & $(-0.01,0.46)$ & 0.0620 & 0.2129 & $(-0.05,0.48)$ & 0.1077 \\
\hline Education level_-high school & -0.1189 & $(-0.28,0.04)$ & 0.1496 & -0.1436 & $(-0.32,0.03)$ & 0.1010 \\
\hline College & -0.1936 & $(-0.36,-0.03)$ & 0.0211 & -0.2261 & $(-0.40,-0.06)$ & 0.0101 \\
\hline Insurance status_-public & -0.2764 & $(-0.46,-0.09)$ & 0.0037 & -0.1834 & $(-0.38,0.02)$ & 0.0700 \\
\hline Private & -0.2186 & $(-0.48,0.04)$ & 0.0974 & -0.1407 & $(-0.40,0.12)$ & 0.2788 \\
\hline SC-general diet & -0.0758 & $(-0.12,-0.04)$ & 0.0004 & -0.0555 & $(-0.10,-0.02)$ & 0.0083 \\
\hline Specific diet & -0.0329 & $(-0.08,0.01)$ & 0.1451 & -0.0368 & $(-0.08,0.01)$ & 0.1025 \\
\hline Exercise & -0.0413 & $(-0.07,-0.01)$ & 0.0035 & -0.0266 & $(-0.06,0.00)$ & 0.0798 \\
\hline Blood Glucose testing & -0.0658 & $(-0.09,-0.04)$ & $<0.0001$ & -0.0512 & $(-0.08,-0.02)$ & 0.0033 \\
\hline IPC-hurried communication & 0.1800 & $(0.08,0.28)$ & 0.0004 & 0.1295 & $(0.02,0.24)$ & 0.0208 \\
\hline Elicited concerns & 0.0145 & $(-0.08,0.11)$ & 0.7506 & 0.0414 & $(-0.05,0.13)$ & 0.3745 \\
\hline Explained results & -0.0424 & $(-0.15,0.06)$ & 0.4186 & -0.0038 & $(-0.11,0.10)$ & 0.9422 \\
\hline Patient-centered decision & 0.0251 & $(-0.06,0.11)$ & 0.5659 & 0.0513 & $(-0.03,0.14)$ & 0.2323 \\
\hline Compassionate/respectful & -0.0346 & $(-0.14,0.07)$ & 0.5215 & -0.0109 & $(-0.12,0.10)$ & 0.8461 \\
\hline Discriminated style & -0.0039 & $(-0.11,0.11)$ & 0.9434 & -0.0818 & $(-0.19,0.03)$ & 0.1403 \\
\hline DDS-total distress & 0.1682 & $(0.11,0.23)$ & $<0.0001$ & 0.0660 & $(-0.00,0.14)$ & 0.0655 \\
\hline Insulin injection frequency & 0.2001 & $(0.10,0.30)$ & 0.0002 & 0.1616 & $(0.04,0.28)$ & 0.0088 \\
\hline Adherence (no missed shots) & -0.4575 & $(-0.60,-0.32)$ & $<0.0001$ & -0.1939 & $(-0.34,-0.05)$ & 0.0104 \\
\hline
\end{tabular}

$B M I$ body mass index, $C l$ confidence interval, DDS Diabetes Distress Scale, IPC Interpersonal Process of Care, LA Latin America, OADs oral antidiabetic drugs, SC self-care

again that adherence is a key factor in attaining treatment targets whereas treatment complexity negatively affects long-term adherence and increases hospitalization rates [37]. The cost of treatment was also identified as a potential barrier to attaining $\mathrm{Hb} 1 \mathrm{c}$ target values, which was confirmed by several other studies [23, 38].

Other factors affecting the attainment of HbA1c target values included level of education, healthy diet, performance of self-monitoring blood glucose, and a hurried communication style in the interpersonal process of care. Certainly, all of them have a common denominator: education.

Several authors have shown, in many populations, that educational programs using cognitive reframing are associated with improved outcomes [39-41]. Furthermore, Brownson et al. also reported that self-management programs for T2DM implemented at the primary care level were cost-effective from the perspective of a healthcare system when considering cost savings as a result of reductions in long-term complications [42].
In LA, we have shown that the implementation of a structured education program for individuals with T2DM (PEDNID-LA, Programa de Educación de Diabéticos No Insulinodependientes en América Latina) significantly improved the clinical and metabolic parameters that were tested and decreased the cost of treatment by $64 \%$ [39]. More recently, the 3-year prospective education study implemented in the province of Corrientes (Argentina; PRODIACOR, PROgrama DIAbetes CORrientes), demonstrated similar clinical, metabolic, and psychological improvements [43]. This study also showed that education, regardless of the method used, is an effective tool to improve the care and outcomes of those with T2DM. However, the combined education of patients and physicians provided the greatest and most consistent and sustained clinical and metabolic improvement at the best drug treatment cost-effective ratio [43].

Similarly, a long-term multi-center education trial implemented in Italy by Trento and colleagues showed that healthcare behaviors, clinical and metabolic 
indicators, and quality of life were significantly better in the intervention group than in the control group [44].

Our study has several limitations, mainly associated with the nature of observational research (i.e., observational studies cannot provide causal evidence of an effect, in our case the real impact of conditioning factors on attainment of HbA1c target values). Baseline data were not available for all patients for all variables considered, thus we used multiple imputation with chained equations, a well-recognized method that accommodates both categorical and continuous variables, to impute missing values. Although this approach assumes that the missing values are missed at random, it is not possible to prove this assumption. Consequently, we also used a complete case analysis approach and results were quantitatively similar. Finally, the demographic, clinical, and psychosocial characteristics of the enrolled patients may be different from those individuals with T2DM in the general population of each country (24); this last bias could be of a lower magnitude because we recruited patients from both endocrinology and primary care practice sites with different practice locations (urban/rural), sizes, and practice types (academic/stand-alone) to maximize the data generalizability.

\section{Conclusions}

The MOSAIc baseline data showed that patients under an initial scheme of insulin treatment in LA and nonLA countries are not achieving appropriate glycemic control, and this analysis identified several conditions that significantly affect the attainment of HbA1c values suggested by international guidelines. Appropriate glycemic control can effectively prevent the development and progression of chronic complications that decrease quality of life and increase cost of care over time. Although some of these factors are not modifiable (e.g., age), most of them can be significantly removed by educational strategies. Therefore, policy makers, particularly in the LA region where health resources are frequently scarce, might seriously consider the wide implementation of educational activities to improve the metabolic control of individuals with diabetes. This strategy could effectively decrease the heavy burden of the disease on health budget, the society, and particularly on individuals with diabetes.

\footnotetext{
Abbreviations

ALAD: Asociación Latinoamericana de Diabetes; ANOVA: analysis of variance; HbA1c: glycated hemoglobin; IPC: Interpersonal Processes of Care; LA: Latin America; MOSAlc: Multinational Observational Study Assessing Insulin use; OADs: oral antidiabetic drug; PEDNID-LA: Programa de Educación de Diabéticos No Insulinodependientes en América Latina; Prodiacor: PROgrama DIAbetes CORrientes; SD: standard deviation; T2DM: type 2 diabetes mellitus; UAE: United Arab Emirates.
}

\section{Authors' contributions}

$\mathrm{BL}$ is responsible for the concept and design the study the analysis and interpretation of data, the drafting the manuscript, and is the guarantor of this work. $\mathrm{BC}$ is responsible for concept and design of the study, the acquisition of data, the analysis and interpretation of data, and critical revision of the manuscript. GF, RM, MEP are responsible for data acquisition and critical revision of the manuscript. OS, JML are responsible of the critical revision of the manuscript. $\mathrm{JJG}$ is responsible for the data analysis and interpretation as well as drafting of the manuscript. All authors read and approved the final manuscript.

\section{Author details \\ 1 Eli Lilly and Company, Tronador 4890, Piso 12, CABA, C1430DNN Buenos Aires, Argentina. ${ }^{2}$ Eli Lilly and Company, Lilly Corporate Center, Indianapolis, IN 46285, USA. ${ }^{3}$ Servicio de Nutrición y Diabetes, Hospital Sirio Libanes, Campana 4658, C1419HN Buenos Aires, Argentina. ${ }^{4}$ School of Medicine of the Federal University of Ceará, Rua Capitao Francisco Pedro, 1290 Fortaleza, Ceara 60430-370, Brazil. ${ }^{5}$ Hospital de Especialidades del Centro Médico de Occidente IMSS, Belisario Domínguez 1000, piso 2., Col. Independencia Gua- dalajara, Jalisco, Mexico. ${ }^{6}$ Eli Lilly and Company, Barranca del Muerto 329-1, Col. San José Insurgentes, Delegación Benito Juárez, Mexico 03900, Distrito Federal, Mexico. ${ }^{7}$ Eli Lilly and Company, Av. Morumbi 8.264, São Paulo, Brazil. ${ }^{8}$ CENEXA, Centro de Endocrinología Experimental y Aplicada (UNLP-CONICET La Plata), Calle 60 y 120, La Plata, Argentina.}

\section{Acknowledgements \\ We thank Beth Mitchell for reviewing the manuscript.}

\section{Availability of data and materials}

The results of this analysis are derived from baseline data from an ongoing study and at this stage the data will not be made available publically until the conclusion of the study.

\section{Competing interests}

Drs. Linetzky, Curtis, Stempa and Martins de Lana are employees of and hold stock in Eli Lilly and Company. Dr. Frechtel has received speaker fees from Sanofi-Aventis, Lilly, Merck Sharp \& Dohme (MSD); is an advisory board member for Sanofi and MSD and has received research funding from NovoNordisk, Sanofi-Aventis, Merck Sharp \& Dohme, Lilly, and AstraZeneca. Dr. Renan received research funding from Eli Lilly, NovoNordisk, MSD, Merck Serono, Novartis, AstraZeneca, Boeringher, Sanofi, Aegerion, Amgen, and Jansen and is on advisory boards of Eli Lilly, NovoNordisk, MSD, Merck Serono, Novartis, AstraZeneca, Boeringher, Sanofi, Aegerion, Amgen, and Jansen. Dr. Escalante Pulido is an advisory board member for Eli Lilly, MSD, Boehringer, Jansen, Sanofi-Aventis, NovoNordisk, Bristol-Myers Squibb (BMS), AstraZeneca, and Abbott and has received research funding from BMS, AstraZeneca, Glaxo SmithKline, Eli Lilly, Sanofi-Aventis, and NovoNordisk. Dr. Gagliardino has received speaker fees from BMS, Eli Lilly, MSD, NovoNordisk, Roche, SanofiAventis and Servier; is an advisory board member for BMS, Eli Lilly, MSD, and NovoNordisk; and received unrestricted research grants from Beta, BMS, Eli Lilly, MSD, NovoNordisk, Roche, and Sanofi-Aventis.

\section{Funding}

This study was sponsored by Eli Lilly and Company.

Received: 13 April 2016 Accepted: 10 July 2016

Published online: 22 July 2016

References

1. UK Prospective Diabetes Study (UKPDS) Group. Intensive blood-glucose control with sulphonylureas or insulin compared with conventional treatment and risk of complications in patients with type 2 diabetes (UKPDS 33). Lancet. 1998;352(9131):837-53.

2. Gaede P, Vedel P, Larsen N, Jensen GV, Parving HH, Pedersen O. Multifactorial intervention and cardiovascular disease in patients with type 2 diabetes. N Engl J Med. 2003;348:383-93.

3. Gerstein HC, Miller ME, Byington RP, Goff DC Jr, Bigger JT, Buse JB, Cushman WC, Genuth S, Ismail-Beigi F, Grimm RH Jr, Probstfield JL, SimonsMorton DG, Friedewald WT, Action to Control Cardiovascular Risk in 
Diabetes Study Group. Effects of intensive glucose lowering in type 2 diabetes. N Engl J Med. 2008;358:2545-59.

4. Duckworth W, Abraira C, Moritz T, Reda D, Emanuele N, Reaven PD, Zieve FJ, Marks J, Davis SN, Hayward R, Warren SR, Goldman S, McCarren M, Vitek ME, Henderson WG, Huang GD, VADT Investigators. Glucose control and vascular complications in veterans with type 2 diabetes. N Engl J Med. 2009;360:129-39.

5. Zoungas S, de Galan BE, Ninomiya T, Grobbee D, Hamet P, Heller S, MacMahon S, Marre M, Neal B, Patel A, Woodward M, Chalmers J, ADVANCE Collaborative Group, Cass A, Glasziou P, Harrap S, Lisheng L, Mancia G, Pillai A, Poulter N, Perkovic V, Travert F. Combined effects of routine blood pressure lowering and intensive glucose control on macrovascular and microvascular outcomes in patients with type 2 diabetes: new results from the ADVANCE trial. Diabetes Care. 2009;32:2068-74.

6. Escobedo J, Buitrón LV, Velasco MF, Ramírez JC, Hernández R, Macchia A Pellegrini F, Schargrodsky H, Boissonnet C, Champagne BM, CARMELA Study Investigators. High prevalence of diabetes and impaired fasting glucose in urban Latin America: the CARMELA Study. Diabet Med. 2009;26:864-71

7. Lopez Stewart G, Tambascia M, Rosas Guzmán J, Etchegoyen F, Ortega Carrión J, Artemenko S. Control of type 2 diabetes mellitus among general practitioners in private practice in nine countries of Latin America. Rev Panam Salud Publica. 2007;22:12-20

8. Gagliardino JJ, Kleinebreil L, Colagiuri S, Flack J, Caporale JE, Siri F, Clark C Jr. Comparison of clinical-metabolic monitoring and outcomes and coronary risk status in people with type 2 diabetes from Australia, France and Latin America. Diabetes Res Clin Pract. 2010;88:7-13.

9. Chan JC, Gagliardino JJ, Baik SH, Chantelot JM, Ferreira SR, Hancu N, Ilkova H, Ramachandran A, Aschner P, IDMPS Investigators. Multifaceted determinants for achieving glycemic control: the International Diabetes Management Practice Study (IDMPS). Diabetes Care. 2009;32:227-33.

10. Shah S, Yang W, Hasan MI, Malek R, Molskov Bech O, Home P. Biphasic insulin aspart 30 in insulin-naive people with type 2 diabetes in nonwestern nations: results from a regional comparative multinational observational study (A(1)chieve). Diabetes Technol Ther. 2013;15:954-63.

11. Commendatore V, Dieuzeide G, Faingold C, Fuente G, Luján D, Aschner P, Lapertosa S, Villena Chávez J, Elgart J, Gagliardino JJ, DIFAR Academic Committee. Registry of people with diabetes in three Latin American countries: a suitable approach to evaluate the quality of health care provided to people with type 2 diabetes. Int J Clin Pract. 2013;67:1261-6.

12. Brown JB, Nichols GA. Slow response to loss of glycemic control in type 2 diabetes mellitus. Am J Manag Care. 2003;9:213-7.

13. Escalante M, Gagliardino JJ, Guzman JR, Tschiedel B. Call-to-action: timely and appropriate treatment for people with type 2 diabetes in Latin America. Diabetes Res Clin Pract. 2014;104:343-52.

14. Grant RW, Buse JB, Meigs JB, University HealthSystem Consortium (UHC) Diabetes Benchmarking Project Team. Quality of diabetes care in US Academic Medical Centers: low rates of medical regimen change. Diabetes Care. 2005;28:337-442.

15. Gough $S$, Frandsen KB, Toft AD. Failure of insulin monotherapy in patients with type 2 diabetes: a population-based study. Diabetes. 2006;55(Suppl. 1):A114.

16. Calvert MJ, McManus RJ, Freemantle N. Management of type 2 diabetes with multiple oral hypoglycaemic agents or insulin in primary care: retrospective cohort study. Br J Gen Pract. 2007:57:455-60.

17. Raskin P, Allen E, Hollander P, Lewin A, Gabbay RA, Hu P, Bode B, Garber A, INITIATE Study Group. Initiating insulin therapy in type 2 Diabetes: a comparison of biphasic and basal insulin analogs. Diabetes Care. 2005;28:260-5.

18. Holman RR, Farmer AJ, Davies MJ, Levy JC, Darbyshire JL, Keenan JF, Paul SK, 4-T Study Group. Three-year efficacy of complex insulin regimens in type 2 diabetes. N Engl J Med. 2009;361:1736-47.

19. Peyrot M, Rubin RR, Lauritzen T, Skovlund SE, Snoek FJ, Matthews DR, Landgraf R, Kleinebreil L, International DAWN Advisory Panel. Resistance to insulin therapy among patients and providers: results of the crossnational Diabetes Attitudes, Wishes, and Needs (DAWN) study. Diabetes Care. 2005;28:2673-9.

20. Philis-Tsimikas A. Initiating basal insulin therapy in type 2 diabetes: practical steps to optimize glycemic control. Am J Med. 2013;126(9 Suppl 1):S21-7.

21. Wallace TM, Matthews DR. Poor glycaemic control in type 2 diabetes: a conspiracy of disease, suboptimal therapy and attitude. QJM. 2000;93:369-74.
22. Davies MJ, Gagliardino JJ, Gray LJ, Khunti K, Mohan V, Hughes R. Real-world factors affecting adherence to insulin therapy in patients with Type 1 or Type 2 diabetes mellitus: a systematic review. Diabet Med. 2013;30:512-24.

23. McEwen LN, Bilik D, Johnson SL, Halter JB, Karter AJ, Mangione CM, Subramanian U, Waitzfelder B, Crosson JC, Herman WH. Predictors and impact of intensification of antihyperglycemic therapy in type 2 diabetes: translating research into action for diabetes (TRIAD). Diabetes Care. 2009;32:971-6.

24. Polinski JM, Curtis BH, Seeger JD, Choudhry NK, Zagar A, ShrankWH. Rationale and design of the multinational observational study assessing insulin use: the MOSAlc study. BMC Endocr Disord. 2012;12:20.

25. Fitzgerald JT, Funnell MM, Hess GE, Barr PA, Anderson RM, Hiss RG, Davis WK. The reliability and validity of a brief diabetes knowledge test. Diabetes Care. 1998;21:706-10.

26. Polonsky WH, Fisher L, Earles J, Dudl RJ, Lees J, Mullan J, Jackson RA. Assessing psychosocial distress in diabetes: development of the diabetes distress scale. Diabetes Care. 2005;28:626-31.

27. Stewart AL, Napoles-Springer AM, Gregorich SE, Santoyo-Olsson J. Interpersonal processes of care survey: patient-reported measures for diverse groups. Health Serv Res. 2007;42(3 Pt 1):1235-56.

28. Toobert DJ, Hampson SE, Glasgow RE. The summary of diabetes self-care activities measure: results from 7 studies and a revised scale. Diabetes Care. 2000;23:943-50.

29. Azur MJ, Stuart EA, Frangakis C, Leaf PJ. Multiple imputation by chained equations: what is it and how does it work? Int J Methods Psychiatr Res. 2011;20:40-9.

30. Ali MK, Bullard KM, Gregg EW. Achievement of goals in US Diabetes Care, 1999-2010. N Engl J Med. 2013;369:287-8.

31. Guzman JR, Lyra R, Aguilar-Salinas CA, Cavalcanti S, Escaño F, Tambasia M, Duarte E, ALAD Consensus Group. Treatment of type 2 diabetes in Latin America: a consensus statement by the medical associations of 17 Latin American countries. Latin American Diabetes Association. Rev Panam Salud Publica. 2010;28:463-71.

32. Riddle MC, Aronson R, Home P, Marre M, Niemoeller E, Miossec P, Ping L, Ye J, Rosenstock J. Adding once-daily lixisenatide for type 2 diabetes inadequately controlled by established basal insulin: a 24-week, randomized, placebo-controlled comparison (GetGoal-L). Diabetes Care. 2013;36:2489-96.

33. Yki-Jarvinen H, Rosenstock J, Durán-Garcia S, Pinnetti S, Bhattacharya S, Thiemann S, Patel S, Woerle HJ. Effects of adding linagliptin to basal insulin regimen for inadequately controlled type 2 diabetes: a 52-week randomized, double-blind study. Diabetes Care. 2013;36:3875-81.

34. Buse JB, Bergenstal RM, Glass LC, Heilmann CR, Lewis MS, Kwan AY, Hoogwerf BJ, Rosenstock J. Use of twice-daily exenatide in Basal insulin-treated patients with type 2 diabetes: a randomized, controlled trial. Ann Intern Med. 2011;154:103-12.

35. Liu L, Lou Q, Guo X, Yuan L, Shen L, Sun Z, Zhao F, Dai X, Huang J, Yang H, Mordes JP, Chinese Diabetes Education Status Survey Study Group. Management status and its predictive factors in patients with type 2 diabetes in China: a Nationwide Multicenter Study. Diabetes Metab Res Rev. 2015;31:811-6.

36. Teoh H, Braga MF, Casanova A, Drouin D, Goodman SG, Harris SB, Langer A, Tan MK, Ur E, Yan AT, Zinman B, Leiter LA, T2DM QUERI Investigators. Patient age, ethnicity, medical history, and risk factor profile, but not drug insurance coverage, predict successful attainment of glycemic targets: time 2 Do More Quality Enhancement Research Initiative (T2DM QUERI). Diabetes Care. 2010:33:2558-60.

37. Lo-Ciganic WH, Donohue JM, Thorpe JM, Perera S, Thorpe CT, Marcum ZA, Gellad WF. Using machine learning to examine medication adherence thresholds and risk of hospitalization. Med Care. 2015;53:720-8.

38. Williams J, Steers WN, Ettner SL, Mangione CM, Duru OK. Cost-related nonadherence by medication type among Medicare Part D beneficiaries with diabetes. Med Care. 2013;51:193-8.

39. Gagliardino JJ, Etchegoyen G, PENDID-LA Research Group. A model educational program for people with type 2 diabetes: a cooperative Latin American implementation study (PEDNID-LA). Diabetes Care. 2001;24:1001-7.

40. Ellis SE, Speroff T, Dittus RS, Brown A, Pichert JW, Elasy TA. Diabetes patient counseling: a meta-analysis and meta-regression. Patient Educ Couns. 2005;52:97-105.

41. Wagner EH, Grothaus LC, Sandhu N, Galvin MS, McGregor M, Artz K, Coleman EA. Chronic care clinics for diabetes in primary care: a system-wide randomized trial. Diabetes Care. 2001;24:695-700. 
42. Brownson CA, Hoerger TJ, Fisher EB, Kilpatrick KE. Cost-effectiveness of diabetes self-management programs in community primary care settings. Diabetes Educ. 2009;35:761-9.

43. Gagliardino JJ, Lapertosa S, Pfirter G, Villagra M, Caporale JE, Gonzalez CD, Elgart J, González L, Cernadas C, Rucci E, Clark C Jr, PRODIACOR. Clinical, metabolic and psychological outcomes and treatment costs of a prospective randomized trial based on different educational strategies to improve diabetes care (PRODIACOR). Diabet Med. 2013;30:1102-11.
44. Trento M, Gamba S, Gentile L, Grassi G, Miselli V, Morone G, Passera P, Tonutti L, Tomalino M, Bondonio P, Cavallo F, Porta M, ROMEO Investigators. Rethink Organization to iMprove Education and Outcomes (ROMEO): a multicenter randomized trial of lifestyle intervention by group care to manage type 2 diabetes. Diabetes Care. 2010;33:745-7.

\section{Submit your next manuscript to BioMed Central and we will help you at every step:}

- We accept pre-submission inquiries

- Our selector tool helps you to find the most relevant journal

- We provide round the clock customer support

- Convenient online submission

- Thorough peer review

- Inclusion in PubMed and all major indexing services

- Maximum visibility for your research

Submit your manuscript at

www.biomedcentral.com/submit 